\title{
Clinical effect of combined controlled-release nifedipine tablets-valsartan therapy on elderly patients suffering from type II diabetic nephropathy with hypertension.
}

\author{
Xiao-Juan Wang ${ }^{1 \#, ~ J i a n-R o n g ~ W u ~}{ }^{2 \#}$, Lin Liu ${ }^{3}$, Qiu Yang ${ }^{3}$, Hui-Lan Yu ${ }^{1}$, Wan-Hong Luo ${ }^{4}$, Zong-Xun \\ $\operatorname{Yan}^{3 *}$ \\ ${ }^{1}$ Department of Nutrition, Affiliated Hospital of North Sichuan Medical College, Nanchong, Sichuan, PR China \\ ${ }^{2}$ Department of Stomatology, Affiliated Hospital of North Sichuan Medical College, Nanchong, Sichuan, PR China \\ ${ }^{3}$ Department of Endocrinology, Affiliated Hospital of North Sichuan Medical College, Nanchong, Sichuan, PR China \\ ${ }^{4}$ Department of Rehabilitation, Affiliated Hospital of North Sichuan Medical College, Nanchong, Sichuan, PR China \\ \#These authors contributed equally to this work
}

\begin{abstract}
Objective: This study aims to discuss the clinical effect of the combined therapy of nifedipine controlledrelease tablets-valsartan on elderly patients who have Type II Diabetic Nephropathy (T2DN) with Hypertension (HTN).

Methods: We recruited 130 elderly patients who have T2DN with HTN and who were admitted to our hospital over the period of April, 2015 to February, 2017. We divided the patients into the control $(n=65)$ and observation groups $(\mathrm{n}=65)$ through the odd-even method. The control group received controlledrelease nifedipine tablets and the observation group received controlled-release nifedipine tabletsvalsartan. We compared the blood pressure level, total therapeutic efficiency, treatment satisfaction, and BUN level of the two groups.

Results: The blood pressure level of the observation group significantly improved relative to that of the control group $(\mathbf{P}<\mathbf{0 . 0 5})$. The total therapeutic efficiency of the control group was $80.00 \%$, which was significantly lower than that of the observation group $(98.46 \%)(P<0.05)$. The treatment satisfaction of the observation group was $96.92 \%$, which was significantly higher than that of the control group $(\mathbf{7 5 . 3 8 \%})(\mathbf{P}<\mathbf{0 . 0 5})$. The BUN level of the observation group was considerably higher than that of the control group $(\mathbf{P}<\mathbf{0 . 0 5})$.

Conclusions: Elderly patients who received controlled-release nifedipine tablets-valsartan for the clinical treatment of T2DN with HTN exhibited significantly improved blood pressure level, total therapeutic efficiency, treatment satisfaction, and BUN levels. Therefore, the reasonable application of controlled-release nifedipine tablets-valsartan therapy can improve the life quality of elderly patients who have T2DN with HTN.
\end{abstract}

Keywords: Elderly type II diabetes, Nephropathy, Hypertension, Nifedipine controlled-release tablets, Valsartan. Accepted on December 13, 2017

\section{Introduction}

The elderly is vulnerable to Type II Diabetes (T2DH), a functional disorder that drastically decreases insulin secretion [1]. Clinical treatment often stimulates insulin secretion in patients to achieve a remarkable effect on T2DH. Diabetes (DH) often increases the probability of suffering from relevant diseases, particularly Hypertension (HTN) [2]. Delaying therapy places patients with $\mathrm{DH}$ at high risk of kidney failure, a life-threatening condition [3]. This study investigates the effect and clinical value of combined controlled-release nifedipine tablets-valsartan for the treatment of elderly patients who have T2DN with HTN.

\section{Information and Methods}

\section{General information}

We recruited 130 elderly patients who have T2DN with HTN and who were admitted to our hospital over the period of April, 2015 to February, 2017. We divided the patients into the control $(n=65)$ and observation groups $(n=65)$ through the odd- 
even method. The control group comprised 26 males and 39 females aged 56-89 y old (mean: $54.29 \pm 6.35)$. Disease course in this group ranged between 6 and 19 y (mean: $10.11 \pm 0.53$ ). The observation group comprised 23 males and 42 females aged 53-90 (54.33 \pm 6.32 average). Disease course in this group ranged between 7 and 20 y $(10.15 \pm 0.49$ average $)$. No significant difference in terms of gender, age, and disease course was found in the two groups $(\mathrm{P}>0.05)$.

\section{Methods}

The two groups first received insulin injections after hospital admission and received specific dietary control. Later, the control group received controlled-release nifedipine tablets, whereas the observation group received controlled-release nifedipine tablets-valsartan. The control group received $25 \mathrm{mg}$ of controlled-release nifedipine tablets twice a day. The observation group received controlled-release nifedipine tablets at the same dosage and frequency as the control group in addition to $75 \mathrm{mg}$ of valsartan twice a day. Each treatment course lasted 6 months. Finally, the therapeutic outcomes of the two groups were compared.

\section{Evaluation standards}

Therapeutic effect: Significantly effective [4,5]: the renal function indexes and disease symptoms of patients were significantly relieved after treatment. Effective: the renal function indexes and disease symptoms of patients were relieved after treatment. Ineffective: the renal function indexes and disease symptoms of patients after treatment remained basically the same as those before treatment.

Treatment satisfaction: Treatment satisfaction was evaluated using a self-made questionnaire, which classified the treatment as very satisfactory, satisfactory, and unsatisfactory. Final investigation results were compared.

\section{Statistical analysis}

All observation data concerning clinical drug effects on elderly patients who have T2DN with HTN were analysed using SPSS19.0. Measurement data (BUN level) were expressed in $\bar{x}$ $\pm \mathrm{S}$ and examined through t-test. Enumeration data were expressed in $\%$ and examined using $\chi^{2}$-test. $\mathrm{P}<0.05$ indicated statistically significant difference.

\section{Results}

\section{Blood pressure level}

The blood pressure level of the observation group has significantly improved relative to that of the control group $(\mathrm{P}<0.05)$ (Table 1).

\section{Total therapeutic efficiency}

The total therapeutic efficiency of the control group is $80.00 \%$, which is significantly lower than that of the observation group $(98.46 \%)(\mathrm{P}<0.05)$. Results are listed in Table 2.

\section{Treatment satisfaction}

The treatment satisfaction of the observation group is $96.92 \%$, which is significantly higher than that of the control group $(75.38 \%)(\mathrm{P}<0.05)$. Results are shown in Table 3.

\section{BUN level}

The BUN level of the observation group is considerably higher than that of the control group $(\mathrm{P}<0.05)$. Results are shown in Table 4.

\section{Discussion}

The elderly are highly vulnerable to T2DN with HTN. Moreover, elderly patients who have T2DN with HTN may experience the life-threatening condition of drastically elevated blood pressure levels [6]. Clinicians should prioritize the reduction of the blood protein level and blood pressure level of elderly patients who have T2DN with HTN before providing specific treatment [7]. Controlled-release nifedipine tablets relieve hypertension by ensuring smooth muscle relaxation and vasorelaxation through decreasing free $\mathrm{Ca}^{+}$concentration in vessel walls [8]. Additionally, this drug exerts protective effects on the kidney. Valsartan can hinder angiotensin II receptors and effectively control vasoconstriction [9]. Clinical therapy with controlled-release nifedipine tablets-valsartan can significantly improve blood glucose level, blood pressure level, repair kidney tubules, and dramatically improve the urinary albumin excretion of patients [10].

In this study, the blood pressure level of the observation group significantly improved relative to that of the control group $(\mathrm{P}<0.05)$. The total therapeutic efficiency of the control group is $80.00 \%$, which is significantly lower than that of the observation group $(98.46 \%) \quad(\mathrm{P}<0.05)$. The treatment satisfaction of the observation group is $96.92 \%$, which is significantly higher than that of the control group $(75.38 \%)$ $(\mathrm{P}<0.05)$. The BUN level of the observation group is considerably higher than that of the control group $(\mathrm{P}<0.05)$. These findings prove the considerable clinical value of controlled-release nifedipine tablets-valsartan for the treatment of T2DN with HTN in elderly patients.

Table 1. Comparison of blood pressure level between the control and observation group $(\bar{x} \pm s, m m H g)$.

\begin{tabular}{lllll}
\hline Groups & Time & $\mathbf{n}$ & $\begin{array}{l}\text { Diastolic } \\
\text { pressure }\end{array}$ & $\begin{array}{l}\text { Systolic } \\
\text { pressure }\end{array}$ \\
\hline Observation & Before treatment & 65 & $103.59 \pm 3.91$ & $169.49 \pm 6.25$ \\
\cline { 2 - 5 } & After treatment & 65 & $84.69 \pm 5.75$ & $109.69 \pm 5.73$ \\
\hline $\mathrm{t}$ & & 21.9137 & 56.8600 \\
\hline $\mathrm{P}$ & & $<0.05$ & $<0.05$ \\
\hline $\mathrm{Control}$ & Before treatment & 65 & $99.19 \pm 4.49$ & $165.15 \pm 6.13$ \\
\cline { 2 - 5 } & After treatment & 65 & $91.02 \pm 4.83$ & $111.79 \pm 4.42$ \\
\hline $\mathrm{t}$ & & & 9.9882 & 56.9251 \\
\hline
\end{tabular}


Clinical effect of combined controlled-release nifedipine tablets-valsartan therapy on elderly patients suffering from type II diabetic nephropathy with hypertension

\begin{tabular}{lll}
\hline $\mathrm{P}$ & $<0.05$ & $<0.05$ \\
\hline
\end{tabular}

Table 2. Comparison of the total therapeutic efficiency of the control and observation groups (cases).

\begin{tabular}{llllll}
\hline Groups & $\mathbf{n}$ & Significantly effective & Effective & Ineffective & Total therapeutic efficiency (\%) \\
\hline Observation & 65 & 55 & 9 & 1 & 98.46 \\
\hline Control & 65 & 39 & 13 & 13 & 80.00 \\
\hline$X^{2}$ & & & & 11.5271 \\
\hline$P$ & & & & $<0.05$ \\
\hline
\end{tabular}

Table 3. Comparison of treatment satisfaction between the control and observation groups (cases).

\begin{tabular}{llllll}
\hline Groups & $\mathbf{n}$ & Very satisfactory & Satisfactory & Unsatisfactory & Total satisfaction (\%) \\
\hline Observation & 65 & 56 & 7 & 2 & 96.92 \\
\hline Control & 65 & 39 & 10 & 16 & 75.38 \\
\hline$X^{2}$ & & & & 12.6389 & $<0.05$
\end{tabular}

Table 4. Comparison of BUN level between the control and observation groups $(\bar{x} \pm s)$.

\begin{tabular}{|c|c|c|c|c|c|c|}
\hline Groups & Time & $\mathbf{n}$ & UAER (g/L) & & BUN (mmol/L) & $\operatorname{Scr}(\mu \mathrm{mol} / \mathrm{L})$ \\
\hline \multirow[t]{2}{*}{$\begin{array}{l}\text { Observatio } \\
\text { n }\end{array}$} & $\begin{array}{l}\text { Before } \\
\text { treatment }\end{array}$ & 65 & $\begin{array}{l}139.29 \\
25.13\end{array}$ & \pm & $6.13 \pm 0.69$ & $75.53 \pm 0.79$ \\
\hline & $\begin{array}{l}\text { After } \\
\text { treatment }\end{array}$ & 65 & $\begin{array}{l}101.39 \\
14.82\end{array}$ & \pm & $4.29 \pm 0.79$ & $59.29 \pm 0.55$ \\
\hline $\mathrm{t}$ & & & 10.4735 & & 14.1429 & 136.0180 \\
\hline$P$ & & & $<0.05$ & & $<0.05$ & $<0.05$ \\
\hline \multirow[t]{2}{*}{ Control } & $\begin{array}{l}\text { Before } \\
\text { treatment }\end{array}$ & 65 & $\begin{array}{l}137.49 \\
24.13\end{array}$ & \pm & $5.82 \pm 1.01$ & $72.79 \pm 0.53$ \\
\hline & $\begin{array}{l}\text { After } \\
\text { treatment }\end{array}$ & 65 & $\begin{array}{l}109.01 \\
16.25\end{array}$ & \pm & $4.82 \pm 0.51$ & $67.29 \pm 0.65$ \\
\hline$t$ & & & 7.8927 & & 7.1255 & 52.8710 \\
\hline $\mathrm{P}$ & & & $<0.05$ & & $<0.05$ & $<0.05$ \\
\hline
\end{tabular}

\section{Conclusion}

Elderly patients who received controlled-release nifedipine tablets-valsartan for the clinical treatment of T2DN with HTN exhibited significantly improved blood pressure level, total therapeutic efficiency, treatment satisfaction, and BUN levels. Therefore, the reasonable application of controlled-release nifedipine tablets-valsartan therapy can improve the life quality of elderly patients who have T2DN with HTN.

\section{References}

1. Lindblom R, Higgins G, Coughlan M, de Haan JB. Targeting mitochondria and reactive oxygen species-driven pathogenesis in diabetic nephropathy. Rev Diabet Stud 2015; 12: 134-156.
2. Amr AEGE, Abdalla MM. Anticancer activities of some synthesized 2, 4, 6-trisubstituted pyridine candidates. Biomed Res India 2016; 27: 731-736.

3. Aggarwal PK, Veron D, Thomas DB, Siegel D, Moeckel G, Kashgarian M, Tufro A. Semaphorin3a promotes advanced diabetic nephropathy. Diabetes 2015; 64: 1743-1759.

4. Zhang J, Zhang Z, Yang B, Jing X, Zhong W, Tang H. Synergistic effect of melatonin and atorvastatin in type 1 diabetic and ischemic injury cardiomyopathic sprague dawley rats. Lat Am J Pharm 2016; 35: 1719-1724.

5. Dounousi E, Duni A, Leivaditis K, Vaios V, Eleftheriadis T, Liakopoulos V. Improvements in the management of diabetic nephropathy. Rev Diabet Stud 2015; 12: 119-133.

6. Suribabu R, Pindiprolu SSS, Tallurt SV, Chintamaneni P, Samidala N. Protective effects of hydroxytyrosol from diabetic peripheral neuropathy in rodents: implications of antioxidant and anti-inflammatory effects. Lat Am J Pharm 2017; 36: 373-379.

7. Rodríguez-Iturbe B, Pons H, Quiroz Y, Johnson RJ. The Immunological basis of hypertension. Am J Hypertens 2014; $27:$ 1327-1337.

8. Liu GM, Xu K, Li J, Luo YG. 7, 8-dithydroxycoumarins protect human neuroblastoma cells from $A \beta$-mediated neurotoxic damage via inhibiting JNK and p38MAPK pathways. Biomed Res India 2016; 27: 591-595.

9. Agarwal R, Flynn J, Pogue V, Rahman M, Reisin E, Weir MR. Assessment and management of hypertension in patients on dialysis. J Am Soc Nephrol 2014; 25: 1630-1646.

10. Motaweih AK, Usova E, Hussain W, Dello Z, Petri T. Combination therapy with nifedipine GITS60mg: subanalysis of a prospective, $12 \mathrm{w}$ observational study (AdADOSE). Clin Exp Hypertens 2016; 38: 71-80. 


\section{*Correspondence to}

Zong-Xun Yan

Department of Endocrinology

Affiliated Hospital of North Sichuan Medical College

PR China 